\title{
Rap Sessions From the Field: Intersectional Conversations With Jemele Hill, Bun B, Fat Joe, and IDK
}

\author{
C. Keith Harrison \\ Reggie Saunders \\ University of Central Florida \& Scholar-Baller ${ }^{\circledR} \quad$ Jordan Brand \& University of Central Florida
}

\begin{abstract}
To end this special issue, Dr. C. Keith Harrison and Reggie Saunders connected with individuals that exist at the intersection of hip-hop culture and sport. This series of interviews begins with Jemele Hill, an American sports journalist and activist. A graduate from Michigan State University, Jemele also served as an adjunct professor at the University of Central Florida from 2012 to 2014 teaching undergraduate sport business management students practical lessons about sport media. Reggie has been an adjunct faculty member at University of Central Florida since 2015, co-teaching innovation and entrepreneurship in sport/entertainment with Harrison. Reggie follows with an interview with Bun B, one half of the Texas rap duo, UGK and currently an adjunct professor at Rice University teaching a course on religion and hip-hop. New York rapper and entrepreneur, Fat Joe weighs in briefly on the topic, and Reggie closes out by interviewing rapper and Washington DC native, IDK. IDK is known for his hit song 24, and has a notable fan in Kevin Durant, National Basketball Association superstar and fellow Washington, DC native.
\end{abstract}

\section{Interview 1: Doctor Harrison and Jemele Hill}

Note: This interview with Jemele Hill was conducted before the helicopter crash and tragic death of Kobe and his daughter Gigi.

Doctor Harrison (Doc): I'm going start off with a little dedication. Over the past few years, I've been asking people to give me examples of the intersection of hip-hop and sport. My late father, Mr. Claude Harrison, for him it was really obvious; the one example that he would take to his grave would be Mike ${ }^{1}$ and Jemele's show. You can imagine when he said that it was based on the history. So, tell me, in your mind, how has that show intersected with hip-hop and sport?

Jemele Hill (J): Wow. What's funny was that it was always unintentionally intersectional. It wasn't because we sat down at a desk and said, "you know what we're going to do is make sure hip-hop intersects with sports." It's who we were and that is the part about hip-hop and those intersections that is so beautiful. It was always organic, you know Mike and I, we're really big hip-hop fans. We grew up on hip-hop. We saw how it matured and from our vantage point, what we could see, [was that] hip-hop being a part of sports was as natural as breathing. So, to not include it never occurred to us. To actually go out of your way to include it, also never occurred to us because that's just what it was. I think that in everything that we tried to do, we always tried to represent a certain level of authenticity and originality, and that is kind of how it spoke to who we were. So yeah, we understood the music the athletes were listening to, we understood the conversations they were having, and people didn't even realize [that] they were having them. We understood all of it because we were, although slightly older, a product of the generation in which they were now fully enveloped. We used to joke all the time that we remembered a time

Harrison is with Scholar-Baller ${ }^{\circledR}$, University of Central Florida, Orlando, FL, USA. Saunders is with Jordan Brand, University of Central Florida, Orlando, FL, USA. Harrison (scholarballer51@yahoo.com) is corresponding author. when hip-hop being associated with the National Basketball Association (NBA) wasn't that cool, and they were trying to do everything possible to make sure that this marriage did not happen. Now, much like star-crossed lovers with a different fate, not like Romeo and Juliet, because we know how that ended up, they couldn't keep it apart, because it was intrinsically burned into the culture of sports and especially basketball.

Doc: I'm just thinking about the dress code.

J: Yeah, the dress code, that's what I'm talking about, like how it was at that time. It's funny that the NBA now is known as the cool and progressive league. We both remember a time when they weren't that cool or that progressive. So, to see them go from "oh my god what are these corn rows and what do these throwback jerseys mean" to [fully] embracing that culture by having hip-hop acts regularly performing during halftime, the NBA All-Star weekend, and the All-star game, and just [completely] welcoming it into the culture, speaks to how powerful hip-hop became. So powerful, [in fact], that people could not even deny it anymore as keeping it out of your sport was considered to be a net loss.

Doc: Would you agree that Jalen [Rose] and [David] Jacoby's show is an extension of your show but with different images?

J: Jalen and I are both from Detroit. Jacoby is somebody who has long respected the culture and hip-hop. I don't think they were trying to follow us; I think they were just trying to follow sports, and they understood that if they want to have these conversations about athletes, sports, and related issues, they needed to be in on this genre. This has always been who Jalen was. This has always been who Jacoby was. So, it was a very natural marriage. I think they looked at where hip-hop was taking certain leagues, sports, and players and understood that if I'm going to adequately cover this league, I need to understand all parts of this conversation they're having.

Doc: So, how far have we come since the Jadakiss and Iverson commercial (that Steve Stoute created for Reebok promoting the Iverson line of kicks beginning in 1996). I'm trying to give us a 
historical perspective of when people were, [referencing] back to your threat comment, what is that? Now, we see that tie in everywhere with hip-hop and sport.

J: Man, we have come eons away from where we used to be. To give everybody a true contextual capture, Donald Sterling, who owned the Clippers for thirty years, never had one conversation with the league or at least, [the league] never brought that [news] to the public about this notorious racist being in his league. Donald Sterling was eventually ousted once the audio capture got out about him and the disparaging remarks. [At that time], Donald Sterling was not considered a threat to the NBA [as he went] years owning the Clippers, being a slumlord, and telling black and brown people that they were inferior. [At times,] comparing them to animals and rodents, and all the things frankly [that] we hear from the president. [They] did not consider [Donald Sterling] to be a threat at all, but the person who [they] got upset [with] was Alan Iverson recording a rap album. That was where we were at one point. So that's why I say this idea that the NBA has become so cool is pretty hilarious to me given their history. Before it became cool to embrace and double down into hip-hop, this is where they stood. It was a threat, so historically that is what triggered it.

Doc: You are getting at a question I wanted to ask, are race and social class tied to hip-hop and sport?

J: Rappers want to be athletes, athletes want to be rappers, that's the way it works. It went from Iverson, who still remains, and look Michael Jordan fans going to hate me when I say this, but I will always contend that when it comes to cultural revolution in the league, authenticity, and all those things, the person you need to look at is not Michael Jordan . . . it is Allen Iverson. He was the one who really changed how players operated. They felt, because of him, more comfortable being who they were. They felt proud of where they were from. They knew, again no disrespect to Michael Jordan, he can't help his upbringing, but Michael Jordan grew up in a very certain life. There was a whole lot of cats that could not relate to the way Michael Jordan grew up, and there were many cats that could relate to the way Allen Iverson grew up. It wasn't just the way he grew up; my man was in prison and John Thompson rescued him. There's a lot of people who can relate to that. I say all that to say, all the things that they used to tear down Allen Iverson became cool and would later be monetized, and that's the way it works.

Doc: Would you argue there is a racial component that exists as well?

J: Definitely, I mean, I think both come from relatable experiences. These two groups of people, entertainers and athletes, have always had a common link and a common bond. There was a certain grind, a hunger, a shared experience that they all could relate to and that they all had to do to get to where they are. A lot of them, whether they be rapping, singing or playing ball, came from challenged neighborhoods and challenged family circumstances. So, it was automatically intertwined. Before athletes could express it, rappers spoke the language and vice versa. Through their play and selfexpression, ball players were conversing with rappers. They were having necessary conversations, but it was as if it happened in two different languages.It's the same reason why you can look at a place like Queensbridge in New York, the hometown to Ron Artest, Noreaga, and Nas. They all knew each other and got madd love for each other, and this can be linked to all these [mutual] experiences because they all grew up in the same environment.
They share this will to want to get out of their circumstances and [to] provide a positive example for the people [still] living in those circumstances. That's why the synergy between these two groups has always been very strong because there is a relatability that's there. When you look at any rapper or athlete that came from a certain neighborhood project I guarantee you, you will find others that came from there., I don't think people who know these stories understand how truly exceptional and how much of an outlier it is that you would have this many talented people in one place that would manage to kind of do the same thing. So, it's that marriage, that intersection, that relationship, that is there because of the shared backgrounds that they all have.

Doc: With that same synergy, let's talk about higher education and hip-hop. In 1991, Howard University taught the first class on HipHop, and now its moved to hundreds of schools and Harvard University has a fellowship named after a rapper, Nasir Jones. Can you speak to how education as a whole, can help strengthen the synergy between sport and hip-hop?

J: We have this idea that kids have the most vulnerable minds, that they are sponges and can observe things but, I think this applies to college students as well. You have been taught that you have to go to college, and you'll make a better life for yourself but, it's also about what happens along the way. A lot of the times you learn how to critically think, and you learn how to open your mind. It's very important, that in institutions of learning, whether they be Howard or Harvard, whether they be Morgan State or Michigan State, that people know that this is a place where you can not only adapt critical thinking, but you can learn to critically think your way through problems. So, I think that academia is the perfect place where people can be instructed about how hip-hop came to be, what it means, and how to contextualize it. Understand that, yes, while you're entertained by it, while you may love the lyrics, and while you may dance to the songs, there was so much more there than you realize. This is the point in young people's lives where their mind is open to accepting new, different, and challenging ideas; so, you have to get them while they are there because once they leave there, I don't know what happens to them. I'm not saying that everybody's mind gets changed in college, what I am saying is, the openness that you have as a college student is something that's very hard to replicate in your adult life after that. That's why it's very important to get it there.

Doc: And it's interesting that most of the classes have been taught as African American studies, Sociology, History, but not often in Business. I'll be jumping into this game this fall, it is the last, or at least one of the last disciplines. Any thoughts on that?

J: Oh yeah. So, here's the thing, in America there's a laziness in our culture where we think things that entertain us don't require work. I don't know where this comes from, but it's a laziness that we have. That's part of the reason why what black athletes go through is always disrespected. It is because people think that they just win the genetic lottery and that's it. They tend to not see that there are people who actually had to work to do this. You can dunk when you are twelve but tell you what, if you don't work on not just dunking but your all-around game you will never make it as a professional. People just don't understand the odds of becoming a professional athlete. You have a better chance of being struck by lightning. They don't respect the amount of work that goes into that. I would say that as it relates to hip-hop artists and musicians, if anybody's ever sat down and had a conversation with a rapper 
about their lyrics, about their bars, and about sound, they're absolute geniuses. Geniuses that we take for granted. So, the business part of it has to be dealt with, so we can understand that they are like businesses. So, if they're trying to get out of the record deal, say like Prince who had a symbol put on his face because he was tired of someone else controlling his talent, they can understand why that happens and what the business is. They can begin to understand that, just because you are talented, doesn't mean you get to be exploited. So, I'm glad that there is a conversation and that academia is getting behind the business aspects of what people do in creative positions. We treat them like they have just been hit with this gene of talent, and that just because they are not like somebody else who pours concrete into the ground for ten hours a day [or that] they deserve to be disrespected because they thought of an idea. It takes a lot to be Tyler Perry. It takes a lot. You couldn't do it because most people can't do what he does. He makes a lot of money because of that. Entertaining you does not come without sacrifice, and we need to know what that sacrifice entails. Which is why the money has to be dealt with, the business has to be dealt with.

Doc: Very insightful. As we near the end, I must admit, I am dissatisfied with the lack of discourse concerning African American and other women of color's involvement in hip-hop and sport. Where are those conversations?

$\mathbf{J}: \mathrm{Ok}$, so, this is really, really complicated because it requires a level of confession for women. I'm going to stick to the music side for now, but I'll get to the sports side as it is the same problem. If you look at the drivers of music and content when it comes to hip-hop, female rappers make songs for women whether they want to admit that or not. They got some hard stuff, that's for the fellas, and for my dawgs and all that. It's SO true. But the songs that get them to cross over ... the songs that make them the most money are: geared towards women. What I find is that I know a lot of people, like Jermaine Dupri who are talking about the fact that he felt like it was strippers on the pole that were rapping. However, the reason that there is a lack of support and frankly a lack of exposure when a female artist doesn't talk about how good they can put it down, and you know what I mean by putting it down, it is not necessarily because men don't support them. It's because women don't support them. It's because we are the ones that listen to a lot of hip-hop. We are the audience that buys the tickets. We are the one that download the song. It is in our hands. Women, in most households, generally control the pocketbook. It's us. Right.

Doc: I agree. And what about sports?

J: There is a very interesting statistic if you look at the National Football League (NFL). NFL fan bases are split. Like 50/50 men and women. You look at women's sports and who doesn't support it? its women. It is largely women. The male audience, I'm not saying it's as big as it is in the NFL, what I'm saying is an extraordinarily high amount of men actually watch women's sports. Other women do not watch women's sports as much. Uncomfortable to talk about so I'm sure some women will disagree and call me all kinds of things. They will say that I' $m$ betraying the gender, but that's the truth. I've seen the research; it is the truth. So, I'm wondering too, and I want to pose this question to other women is why don't you: a. support women's sports or b. support women in entertainment? Why do you only support women who talk about certain things. That's what it boils down to essentially. Cardi B is huge and deserves to be huge because she's very talented. Just look at her audience. Right. Primarily women are driving Cardi B. It's not a lot of dudes that are going to be rapping "I like it like that." Then I think about Rah Digga and Queen Latifah. I am not saying that women did not support them, but the levels of women that supported them versus men is not comparable.

\section{Doc: Adina Howard.}

J: Oh my god, like Adina Howard, she speaks to a female audience. Rah Digga and the things she talked about or even my girl Rapsody, what she talks about they don't. Their message doesn't relate as much to what female consumers tend to get in hip-hop. I love me some City Girls, but I also love Rapsody. It's ok to have two different consciousness. That is what hip-hop is all about. You got your fun stuff. You got your play stuff. You've got your hits. However, generally speaking what I have found is that a lot of what's missing is why these conversations aren't being had. They aren't being had because women have dropped the ball on having them. That's not to say the same misogynistic mechanisms are not in place because I'm not letting men off the hook either. But it is to say that some of that is because we have not been great at supporting other female artists.

Doc: Yeah, just the intersection. Queen Latifah played high school basketball. I mean it gets left out at times. Ashanti ran track and had a full ride to Princeton. I think women in general are not seen as influencers with the tie in of hip-hop and sport and in particular women of color.

J: You want to ask a real interesting question? What I'd love to know is why don't men wear women's basketball shoes? As in, "look I got some Candace Parkers, [they are the most comfortable shoes I've ever had in my life .. . like these shoes are amazing." But you never see dudes rock female players kicks.

Doc: Remember when Nas rocked the kicks from the point guard of Notre Dame, Skylar Diggins? That was so important.

J: It was. That's the support that we need to see from men. People in his position need to do that. One of the most beautiful things that happens on social media, whenever it's a WNBA game, especially a really good one, WNBA playoffs for example, LeBron has been constantly tweeting about watching women's basketball. You know that's a big thing in terms of just seeing the support. Kobe has all daughters; his oldest daughter is a $\mathrm{h} * 11$ of a basketball player. Kobe is at the WNBA All Star game at the time of this taping. He is there, and he has been there all weekend, because his daughter loves the WNBA. He comes to more Sparks games than he does Lakers games, and it's not even close, not even close. It is because he understands, not just the importance of exposing his daughter to that, but also because he has a daughter who is actually trying to be a women's professional basketball player. He respects the sport. Most men who are players, when you talk to them, they will tell you the game and the way it's supposed to be played. The women play it that way. That is what they sort of look up too. There's always been this synergy between male and female basketball players. So, I find that to be very inspiring and I find that to be very necessary. It's that men have to understand that you can't just be the dude who is like oh I respect women cause of my mother, my sister, and my grandma. Like you can't be just that dude. We need you to be actively respecting us. We need you to respect and champion us just because we deserve it. And that's the difference, right? 
Doc: Yes, its intrinsic versus extrinsic. On November 2nd, North Carolina Central is going to play Howard University. Howard University is one of our Scholar-Baller ${ }^{\circledR}$ schools, as we have a partnership with Coach Ron Prince. It is Scholar-Baller ${ }^{\circledR}$ day, and we're going to celebrate every player on both teams with a 3.0 or better. Can Hip-Hop culture, as a part of education and sport, be helpful and influential in pushing the message that school is cool, with the Scholar-Baller ${ }^{\circledR}$ concept?

J: It can definitely be really helpful. I think what happens is that black people, in these positions of influence in hip-hop or entertainment or in general, are not aware of how much power we actually have and what we can do with that. Look at a lot of the fabric of HBCUs, hip-hop runs through their DNA. There's no question about that, and there are a lot of hip-hop artists that went to HBCUs, Puffy, right ... Wale went to Bowie State and like them there's a lot more.

Doc: 2 Chainz, Alabama State got his degree which is why he spits rhymes about the NCAA on one of his more recent albums.

J: 2 Chainz, totally. In fact, hip-hop had some of its most prolific and best artists come from HBCUs. It's incumbent on them to push that mission, because I think that at the end of the day, this is what will close the racial wealth gap and will help black Americans change certain economic realities. A lot of that starts with the support of HBCUs. If we changed the level of support that we have for them, then we can mainstream them in the culture. Then, much like you saw in the heyday of HBCUs, a black middle and upper class will rise from that. That is very different than any other mechanism. I mean people have to remember that there was a time and it's so easily forgotten. Unfortunately, it is not taught that HBCU's were the only answer. That was the only place we could go before segregation happened and even when segregation or desegregation happened, they did not want us there. It was the place where arms have always been open, HBCUs. I really think, it is the foundational building block and I say this as somebody who went to a PWI, predominantly white institution. It is the foundational building block of black empowerment, success, and advancement. There's not debate about it.

Doc: Absolutely, well Jemele, both of us have a mentor in Dr. Harry Edwards. In his heyday, it was Jazz and sport, and in ours it's hip-hop and sport. I can't wait to see what's next, and I think that for something to overtake hip-hop, it is going to have to be a powerful cultural influence, and I hope I get to live to see it.

J: Might not happen, might not happen!

Doc: Yeah, it's powerful how something began with two turn tables and a microphone and it's interesting to see that flat tops and timbs are coming back full circle.

J: Right, you know what they used to say about hip-hop when we were growing up is that hip-hop was our CNN. I think it was N.W.A.

Doc: Sure, Chuck D was one of the first to say that hip-hop and rap music was our CNN.

J: It was Chuck D, that said it like it was. This was before we had the internet, before we had all this social media stuff, it was like you learned from them. I didn't know, growing up in Detroit, anything about Compton, Cali, but you know who taught me about it, N.W.A., Ice Cube, Eazy E, that's who taught me about what was happening in LA. I was like oh, so its hood all around the world. Oh, I get it like, there's relatable stuff that's happening there and that's [what is] happening here. They rapped about it and it was just such an amazing connection because you realize through these associations and through listening to music that you didn't just hit the unluckiest number on the lottery chart. It was happening everywhere and [through the music] you understood poverty, gun violence, and that institutional racism was an international problem. You realize it was not just a Detroit problem. It was not just a New York problem. It was literally an American problem. So, that's what I thank them for: being my first teachers and for opening my mind about what was happening in this country through them.

Doc: A great place to end, is we have work to do in this country.

J: We Do!

\section{Interview 2: Reggie and Bun B}

Reggie: How does hip-hop culture intersect with sport?

Bun B: The initial intersection of sports and hip-hop comes from upbringing. There's a shared experience that many hip-hop artists have with athletes based on the environment they're raised in. The community they grow up in, as well as the need to become successful in spite of those circumstances, fuels the drive that's necessary to motivate themselves and excel in their respective fields. If there's one particular individual that is the essence of both of these worlds, look no further than Allen Iverson. Having the pure athletic ability necessary to succeed in professional basketball, along with the look and feel normally associated with people from the hip-hop world, make him iconic in both communities. Mix that with his crossover moves and with the braids and tattoos and there you are.

Reggie: Are hip-hop artists and athletes exactly the same culturally speaking?

Bun B: The similarities are a few but resonate deeply. Many of them come from the same inner-city neighborhoods. They went to the same schools. They have similar life experiences. There's a need to signify themselves in the eyes of those they commune with as well as look up to. It's also often seen as the only way to beat the odds and overcome their life circumstances. The major influences in their everyday lives are the successful people they see in their everyday lives - athletes, musicians, or drug dealers. They realize the benefits of the drug trade come quicker than the others, but the trade-off of violence and jail, or even death, isn't worth the rewards so they find themselves focusing their energy on the music or the sport. That's where the difference comes in. While both have mental aspects, it's the pure physicality of sports that separates them. You don't have to be in peak physical shape to excel in hiphop. But it's a necessity when it comes to athleticism.

Reggie: How has the intersection of hip-hop and sport evolved over time?

Bun B: As the worlds of hip-hop and sports grow older, as it pertains to the last 40 years, the mutual respect of people from both walks of life have merged significantly. Many rappers use sports references to reinforce their lyrics. Comparing themselves to people like Michael Jordan, Bo Jackson, LeBron James and others becomes a way of signifying their greatness. Also, we see the 
professional athlete's personal style and swagger taking on more of a hip-hop artist's look and feel. It allows them to show their edginess and helps them to express a more street-savvy persona.

Reggie: Do you feel hip-hop and sport transcends generations?

Bun B: In today's world, more than ever young people believe the older generations have little to no understanding of the world they live in. Often, they feel their elders either don't know or don't care to know about their cultural likes and influences. Using sports and hip-hop references in casual conversations and being knowledgeable about the next generation of sports and hip-hop stars shows a concerted effort on our part to try and bridge the gap. It gives us a common ground to build a deeper understanding of each other respective worlds. Sometimes that can make all the difference in the world.

\section{Interview 3: Reggie and Fat Joe}

Reggie: Joe what are your thoughts and insights (briefly) on the intersection of hip-hop and sport?

Fat Joe: Artists love sports and athletes love music. It's all relevant and woven at the hip, one doesn't exist without the other. I use sports all the time mainly basketball to inspire rhymes. For example, before me Public Enemy rapped "I'll go down your throat like Barkley," it's always been one.

\section{Interview 4: Reggie and IDK}

Reggie: What is the intersection of hip-hop culture in sport? (e.g., athletes and artists)

IDK: We all know music (hip-hop especially) has an immense effect on a person's mood. Athletes often use hip-hop as motivation to get on the field or court and deliver. The energy of Hip-Hop and sports go hand in hand, almost to the point where you can't have one without the other. Try playing NBA $2 \mathrm{~K}$ with music shut off.

Reggie: How are they (hip-hop and sport) similar? And how are they (hip-hop and sport) different if at all?

IDK: One similarity with sports and music is the fact that they are both a display of energy, usually fueled by experience and the drive to be great. However, I believe one major difference between sports and hip-hop is that music is used to provoke physical energy whiles sports are the actual display of physical energy.

Reggie: How has sport helped/assisted you with your artistic endeavors now?

IDK: Lately, I've noticed that a lot of basketball players have been showing an appreciation for my music. That experience has driven me to appreciate and watch the game even more. In watching and paying attention to basketball, it helped me realize how important my inner drive to be great is. It's pushed me to practice my sport even more, in order to deliver at the highest level. Especially with everything that's gone on with Kobe and the legacy he's left behind (RIP).

Reggie: What way(s) can we use sport and hip-hop to empower our youth to be educated and learn?
IDK: These days the traditional Marvel character like Spider-Man and or Wolverine are a little too out of reach to be our youth's superheroes. Even if they act as so during early childhood, things change during adolescence when reality strikes. Today rappers and athletes, especially in the lower-class black communities, seem to be the most influential and positive role models. I am with this- the sky is the limit as long as we as successors are willing to give back.

\section{Coda}

The above conversations demonstrate some key themes with the intersectionality of hip-hop culture(s) and sport. The above interviews give us participant-observer-creators in "real time" in the area in which this special issue is focused. First, these interviews, conversations, and dialogues with cultural influencers like the individuals in this section are unique - this is one of the first instances that these kinds of identities have ever been presented in an academic journal on sport and/or hip-hop, which is important in terms of privileging and representing voices that are often marginalized or discounted in academic discourse. Future research should examine in-depth how education, politics, business, and so on land in the "sweet spot" of hip-hop and sport.

Second, generational hip-hop preferences are clearly transparent across the era of which artists and athletes coexist which is also apparent in this section. This phenomenon is prevalent beyond hiphop and present with other genres such as country, R\&B, Rock-nRoll. For instance, NBA great Bill Walton was closely tied to the group The Grateful Dead, and today, many White athletes have grown-up on hip-hop being mainstreamed, which resulted in many of their favorite artists being Black. Generationally, Professor Emeritus Harry Edwards often assigned the autobiography of Miles Davis to his sociology of sport course at University of California, Berkeley, as this music legend was of his era when Jazz was at its peak. Parallel to Dr. Edwards, while at the University of Michigan, the author Harrison continued this trend, assigning Michael Eric Dyson's book on Tupac Shakur to C. K. Harrison's sport management and communication race relations, cultural images, and sport course to further highlight the intersection of sport and music. Future research related to the topic of this special issue should examine other intersectional dynamics and contexts of sport and hip-hop, particularly across generations and, indeed, geographic landscapes. One popular show that integrates various generations across artists and athletes is The Shop: Uninterrupted produced by LeBron James and Maverick Carter. The show also includes business leaders, actors, and other cultural influencers that all coalesce around the concept of being an elite performer at their craft regardless of race or gender.

Third, more investigation is needed about the intersectionality of hip-hop culture(s) and sport. Globally, we need to know more about youth, gender, sexuality, race, class, and performance. As Jemele Hill alluded to in her interview, we need to hear and privilege the voices of women in the conversation of sport and hip-hop. There are so many fruitful and potential insights from this exchange, and even in North America, we have only scratched the surface with how these two performance cultures relate to one another. For example, during the pre-events and various media gatherings to discuss the global spectacle in 2018 (the Super Bowl), former NFL star Deion Sanders asked hip-hop artist and entrepreneur Rick Ross to name what positions some rap artists might play, and here is a list of his responses to Deion Sanders stating that "Rick you know about football, you know a lot about sports, and you know a lot about people — and you played the game": 
Lil Wayne Running Back (RB)

Jay-Z Quarterback (QB)

Meek Mill Wide Receiver (WR)

Migos Running Back (RB)

TI Cornerback (CB)

Rick Ross (Center)

In the final analysis, Rick Ross illuminates one of the major purposes of this special issue and this last section of interviews: Hip-Hop culture(s) and sport impact the societal landscape individually, and collectively, and there is serious crossover when examining the parallels of each. Artists and athletes at their core are elite performers (ballers) and there is a mutual admiration and respect that each pays one another most of the time for their public persona and being at the top of their game.

\section{Note}

1. Michael Smith was an ESPN host and commentator for 15 years, and cohosted ESPN SC6 with Jemele Hill, as well as the His \& Hers podcast.

\section{Acknowledgments}

The authors thank Delaney Chariker (University of Central Florida) for transcribing Jemele Hill's interview and also thank Jasmyn Mackell (University of Central Florida) and Danielle McArdle (Seton Hall University) for their assistance with editing previous drafts of this article. 